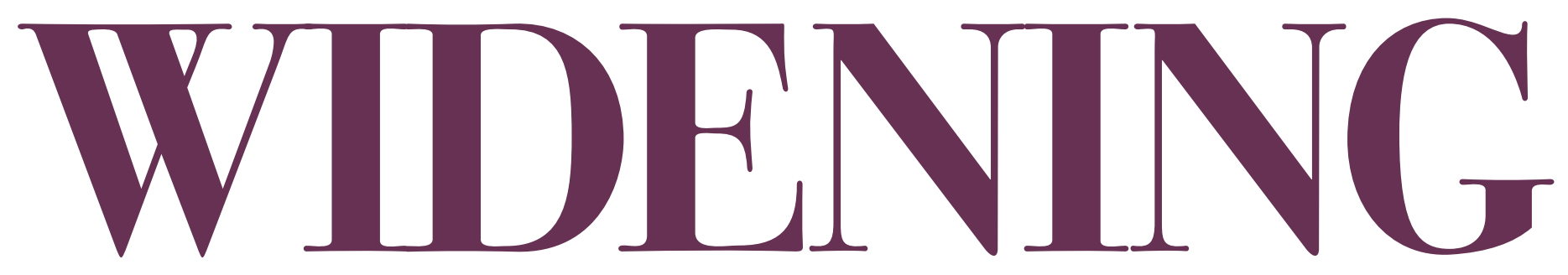

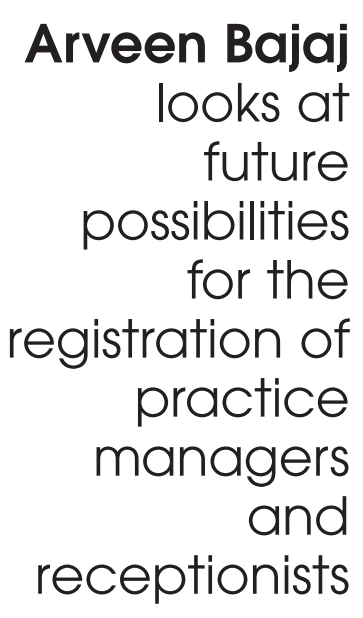

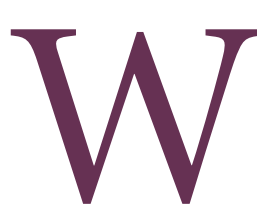
ith $\mathrm{PCD}$ registration set to change the landscape for the dental team the outlook for the groups that are to be registered looks positive. However, while it is compulsory for certain groups of PCDs to be registered with the General Dental Council (GDC) around the end of 2004, it is not for groups such as practice managers and receptionists.

While the GDC recognises the essential role that practice managers and receptionists play in the service provided by dental teams to patients, its efforts have been concentrated upon registering categories of PCD who have a clinical involvement with patients, such as dental nurses and dental technicians. For that reason, dental practice managers and receptionists are not one of the groups required to register.

Hew Mathewson, President of the GDC comments, 'As a practitioner myself, I recognise how vital a part of the team the receptionists and practice managers are. For example, they are involved with dealing with highly confidential information. While we are not going to register them in the immediate future, it is something that we may think about in the longer term.'

The different groups' representative asso- ciations also echo this view. Glenys Bridges, secretary of the British Dental Receptionist Association (BDRA) outlines the important role receptionists have to play within a dental team.

'The BDRA would welcome a decision to register receptionists with the GDC, even although we understand the reasons why this is not possible at the present time. We believe that the professionalism of the reception is the shop window for the practice. Therefore there are requirements for training and qualifications, not least to ensure that receptionists are fully aware of the ethical and legal obligations placed on their employers by the GDC. Trained and registered receptionists would be able to respond appropriately and be accountable for their responses to matters and requests that potentially contravene rights and responsibilities as they arise.'

However, not all groups feel the same way. Bridget Crump, Chairman of the British Dental Practice Managers Association and Vice Chairman Polly Toms, feel registration is needed only for those that are in the clinical environment and where there are public protection issues involved. 'At the moment we personally don't feel it necessary for practice managers to be on the GDC register and instead we recommend that our members should be registered with the Institute of
Leadership and Management or similar business management organisations.'

The question of education opportunities and accessibility for different members of the dental team has often been problematic in the past, and there are still challenges faced by members of the team who are trying to gain certain qualifications and training. Hew expresses particular concern about education and training: 'One of the things that I am increasingly worried about is absence of Department of Health money to fund topup-courses and new education. I think there is a over reliance on the NVQ, which doesn't really suit everyone and so we think there is the need for the national exam to keep going.'

He adds: 'Accessibility to some courses and education is varied across the UK. There are quite significant programmes of education and up to date learning for PCDs in some places while elsewhere it is very sparse indeed.'

Glenys acknowledges that the regional availability of courses can be patchy, but adds that the BTEC qualifications are offered via open learning, which is the most popular format, as on a practical level many dental practices cannot spare receptionists to go on courses for extensive periods. She asserts that the BDRA work closely with the Dental 


\title{
registration:
}

Resource Company to offer a national qualifications framework award for dental receptionists.

'The BTEC Advanced Award in Dental Reception Qualifications is an NVQ level 3 equivalent. The available training for receptionists ranges from the BTEC qualification to add-hoc sessions provided by Health Authorities, the Radcliffe course and inhouse programmes within the practices.'

However, the BDPMA believe that more practice owners need to be persuaded to budget for releasing practice managers during normal working hours. 'We need to help them to understand the benefit for them and their businesses of having qualified practice managers and therefore to facilitate and fund their training.'

Practice manager Margaret Wilson says, 'I think it would be a good idea for practice managers and receptionists to be registered with the GDC eventually. In the case of practice managers it would be a great advantage for them, as a good practice manager needs to be able to deal with any surgery problem, and this requires a very good understanding of the practical side of dentistry as well as the book keeping side.'

Expanding on this, Bridget and Polly assert that the Introduction of Options for Change and the new PCT contract in 2005 will expand the existing role of the practice manager and smaller practices will need the help of a practice manager to cope with the new funding and contracts, and perhaps the Primary Care Trusts may need the help of roving practice manager.

If the net does widen in the future to involve practice managers and receptionists, the same debate could apply to oral health promoters who can come from a huge variety of backgrounds including dental and health promoting,

According to the GDC, after registration is complete, the next stage is ongoing education for PCDs and revalidation of the whole dental team. Glenys believes that registration of practice managers and receptionists would be beneficial for the group as well as the dental team as a whole.

'It has taken many years for the professionals and the establishment to arrive at dental nurse qualification and the work this has required will make it easier for other groups to follow in due course. Practice $m$ anagers and receptionists must work for status and recognition, as dental nurses and other PCDs have.'

\section{The lab assistant loophole}

\author{
Under current rules laboratory process
}

workers will not be required to register with the GDC, but this could undermine the whole statutory registration process for PCDs, reports Caroline Holland.

The vexed issue of dental laboratory

process workers and whether they

register with the General Dental Council

is still under discussion despite the fact

that statutory registration for technicians

is due to be introduced later this year.

The GDC has decided unqualified

workers, known as process workers or

lab assistants, can work in laboratories

provided they are supervised by RDTs

(Registered Dental Technicians). The

GDC believes it can regulate dental

technicians effectively in this way.

However, the Gateway group, an

umbrella organisation representing all

the technicians' organisations including

the Dental Technicians Association, the

Dental Laboratories Association and the

Clinical Dental Technicians Association,

wants the GDC to change its policy.

Antony Townsend, chief executive of

the GDC, met representatives of the

group in January. The meeting was later described by the GDC as positive and it was agreed that the Gateway group

would come up with a briefing paper

which would go to the GDC's

registration committee.

In the briefing paper, Gateway group members will argue that everyone working in dental technology should be registered. They are suggesting that

those who are qualified or who have

appropriate experience can be

registered while those who are not

should be in a new trainee category

and have seven years in which to

qualify.

They believe that if there is a member of the laboratory who is not qualified or in training it creates a loophole which will undermine the whole registration process. They say that under the GDC's plans for laboratories, a large

organisation with a high turn-over could have one registered dental technician
(RDT) responsible for the work of many process workers.

It is also argued that if a technician is erased from the register he or she will be able to continue working in the industry as a process worker, escaping the full impact of the disciplinary process as it currently affects dentists. By creating a different registration structure for technicians, according to Gateway group members, their transition from an industry to a profession is being

impeded.

Chris Allen, chief executive of the Clinical Dental Technicians Association, said that in the past there were many more unqualified than qualified technicians and if that situation was allowed to continue, it would be a nonsense.

'There is a determination to ensure that within seven years of the register being created, everyone working in dental technology is a registered technician.

He added: 'Our interest in this is that RDTs will be able to train as clinical dental technicians. Unless there are high standards in dental technology, it will affect the quality of the trainees who come forward.'

Laboratory owner Steve Mason, who employs three qualified technicians in his own lab, commented: 'This is flying in the face of what everyone wants. There are labs which have a production line and use one person for each stage of the process. Nevertheless, each stage is important and being a technician is a skilled job. The whole process is being devalued.'

If the Gateway group do not manage to persuade the General Dental Council to reverse its decision, it is likely that they will turn their attention to lobbying the Government. 


\section{registration}

Registration for PCDs at the GDC has been covered in the there is some confusion over what people need to obtain to give everyone a better idea of what they may or may This table is for the transitional period of 2 years from date

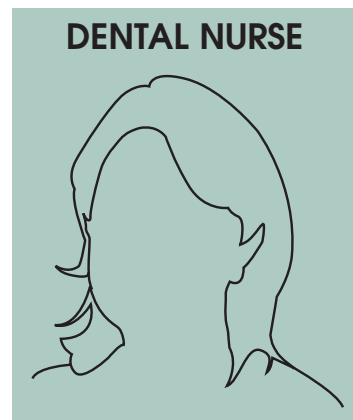

DENTAL HYGIENISTS

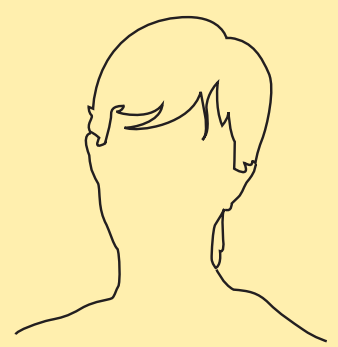

\section{DENTAL THERAPISTS}
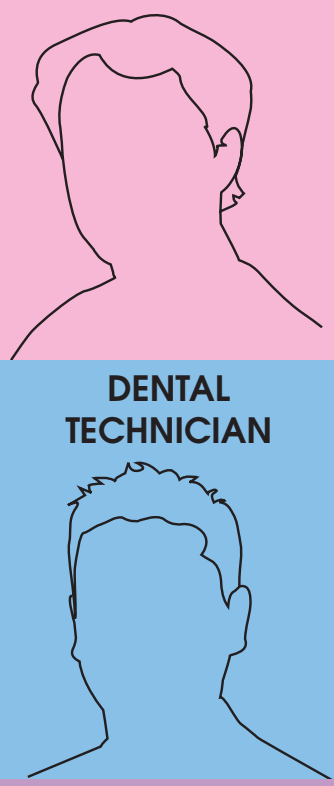

MAXILLOFACIAL

PROSTHETISTS AND TECHNOLOGISTS

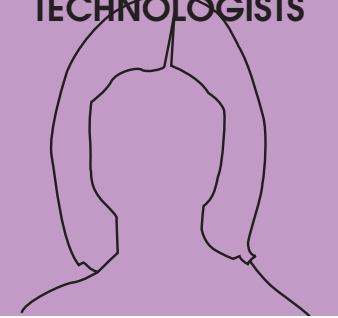

\section{Holder of any of the following?}

- National Certificate from the National Examining Board for Dental Surgery Assistants

- Certificate of Proficiency in Dental Surgery Assisting from a dental hospital recognised by the Association of Dental Hospitals

- BTEC National Certificate in Science (Dental Surgery Assisting or Dental Nursing)

- Full SCOTVEC Certificate in Dental Surgery Assisting or Dental Nursing

- Royal Navy - Part III DSA Training (Certified)

- Army - Class 2 Dental Clerk Assistant Trade Training

- Royal Air Force - DSA Training and Trade Ability Test B

- Dental Defence Agency - Basic Dental Nurse Training and Individual Development Portfolio Stage 1 (IDPS1)

\section{Holder of any of the following?}

- Certificate of Proficiency in Dental Hygiene (awarded by CEB)

- Diploma in Dental Hygiene (awarded by CEB) these are the diplomas given to hygienists who chose to update from a certificate to a diploma. Since the demise of the CEB, these diplomas are awarded by the GDC

- Ministry of Health Certificate in Oral Hygiene

Current or previous enrolment?

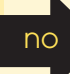
no
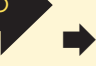

yes

\section{Holder of any of the following?}

- Certificate of Proficiency as a Dental Therapist

- GDC Certificate of Proficiency as a Dental Auxiliary

- Certificate of the Committee of Management of the School of Dental Auxiliaries, New Cross

\section{Holder of any of the following?}

- City and Guilds Final Certificate in Dental Technology

- Qualifications awarded by Technicians Education Council or Scottish Technicians Education Council

- BTEC National Diploma in Science (Dental Technology)

- BTEC Diploma in Dental Technology, Lambeth College, London

- SCOTVEC Higher National Certificate in Dental Technology

- Army - Levels 1, 2 and 3 (Dental Technology)

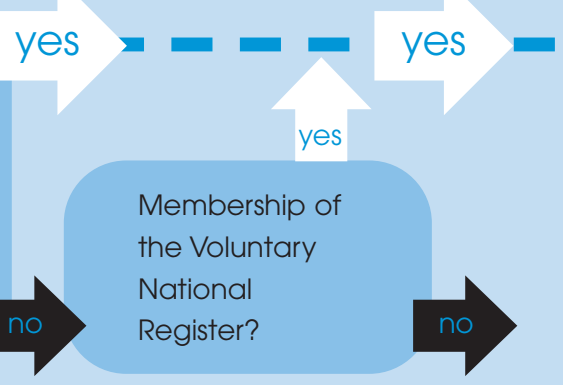

yes $=$ yes
Holder of the following?

City and Guilds Advanced Certificate in Maxillofacial Prosthetics and Technology
Full membership

of the IMPT?

20 spring 04

vital 
